\title{
Patient Safety-Related Incidents and Daylight Saving Time Transitions
}

J Gen Intern Med 36(4): 1120

DOI: $10.1007 / \mathrm{s} 11606-021-06599-7$

(C) Society of General Internal Medicine 2021

$\mathrm{D}$ ear Editor,

We read with interest the recent article by Kolla and colleagues. ${ }^{1}$ We agree with their conclusion that spring forward transition into daylight saving time (DST) may be associated with increased safety-related incidents (SRIs) in a healthcare setting and countermeasures should be considered to mitigate this risk. We applaud the authors for their work in this understudied area.

The authors reviewed voluntarily reported SRIs that occurred 7 days prior and following spring and fall time changes at Mayo Clinic, a large healthcare organization including sites at multiple states. Data from all sites located in states that implement DST was included in the study. As such, data from a major hospital, Mayo Clinic, in Arizona was excluded. US statute allows state-level exemption from DST, and this exemption has been claimed by Arizona. ${ }^{2}$

The current findings, while suggestive, do not exclude effect due to time-of-year. Indeed another study ${ }^{3}$ from Australia demonstrated an annual cycle with number of SRIs peaking in October (spring in the southern hemisphere).

Comparison of the findings of Kolla et al., with data drawn from Mayo Clinic, Arizona could prove valuable in evaluating the hypothesis that the increased rate of SRIs is associated with the switch between standard time and DST. A review of data from Mayo Clinic, Arizona, should be undertaken, to determine whether rates of SRIs demonstrate a similar uptick during the time of spring and fall switch.
We add that further investigation may support these results and additional work is required to understand which countermeasures would be most effective to mitigate this risk.

Muhammad A Rishi, MBBS

Saleha Chaudhry, MBBS

Muhammad A. Rishi, MBBS ${ }^{1}$

Saleha Chaudhry, $M B B S^{2}$

${ }^{1}$ Department of Pulmonology, Critical Care, and Sleep Medicine, Mayo Clinic Health System,

1221 Whipple Street, Eau Claire, WI 54701, USA

${ }^{2}$ Department of Internal Medicine, Mayo Clinic Health System,

Eau Claire, WI, USA

Corresponding Author: Muhammad A. Rishi, MBBS; Department of Pulmonology, Critical Care, and Sleep Medicine, Mayo Clinic Health System, 1221 Whipple Street, Eau Claire, WI 54701, USA (e-mail: rishi.muhammad@mayo.edu).

\section{REFERENCES}

1. Kolla BP, Coombes BJ, Morgenthaler TI, Mansukhani MP. Increased Patient Safety-Related Incidents Following the Transition into Daylight Savings Time. J Gen Intern Med 2020.

2. Rishi MA, Ahmed O, Barrantes Perez JH, Berneking M, Dombrowsky J, Flynn-Evans EE, Santiago V, Sullivan SS, Upender R, Yuen K, AbbasiFeinberg F, Aurora RN, Carden KA, Kirsch DB, Kristo DA, Malhotra RK, Martin JL, Olson EJ, Ramar K, Rosen CL, Rowley JA, Shelgikar AV, Gurubhagavatula I. Daylight saving time: an American Academy of Sleep Medicine position statement. J Clin Sleep Med 2020.

3. Buckley D, Bulger D. Trends and weekly and seasonal cycles in the rate of errors in the clinical management of hospitalized patients. Chronobiol Int 2012; 29: 947-954.

Publisher's Note: Springer Nature remains neutral with regard to jurisdictional claims in published maps and institutional affiliations. 